6.3 Except for the office of Secretary-Treasurer, the term of office for each position shall be one year, or until a successor is elected providing, however, that the incumbent in an office remains eligible for re-election. The term of office of the Secretary-Treasurer shall be three years renewable for one term not to exceed three years. In the event that the incumbent does not intend to stand for re-election, the Board of Directors must instruct the Nominating Committee, at least nine months prior to the beginning of the third year of the Secretary-Treasurer's term of office, to receive nominations for the office of Secretary-Treasurer-Elect, such office to be held during the last year of the Secretary-Treasurer's term.

\title{
Nominations à la direction de l'Association canadienne de science politique
}

Selon les mesures de l'article VIII, paragraphe 2, de la constitution, le comité de nomination invite les membres de l'Association canadienne de science politique à présenter des nominations au poste de président désigné, vice-président, secrétaire-trésorier, et conseillers (6) du Bureau de direction, et au poste de membres (3) du comité de nomination. Les nominations doivent parvenir au secrétaire-trésorier (a/s Carleton University, Colonel By Drive, Ottawa, Ontario K1S 5B6) avant le 15 janvier, 1979.

Les nominations devraient tenir compte d'une répartition géographique qui comprendrait les régions suivantes: les provinces de l'Atlantique, le Québec, l'Ontario, les provinces de l'ouest et la Colombie-Britannique.

Seules les nominations reçues avant le 15 janvier 1979 seront inclues dans la liste présentée aux membres par le comité de nomination. Cependant, le nom d'autres candidats pourra être ajouté à la liste des candidats par l'action conjointe de deux membres qui, à cet effet, devront remettre au secrétaire-trésorier, avant minuit du premier jour la réunion annuelle, un avis de nomination signé par le candidat et par eux-mêmes.

Extraits de la constitution de l'Association canadienne de science politique, au sujet des elections

La Constitution en entier sera publiée, dans un avenir rapproché, dans «Le Bulletin». Des copies de la Constitution sont disponibles au Secrétariat en tout temps.

\section{Article VIII: Elections}

8.1 Le comité de nomination, sera composé du président (sans droit de vote) et de trois membres de l'Association non membre du Bureau de direction et qui seront élus annuellement. (Le cas échéant, le président devra désigner des remplacants.) 


\section{Article VI: Les Officiers}

6.1 Les administrateurs de l'Association sont le président, le président-désigné, un vice-président, un secrétaire-trésorier et durant la demière année du mandat du secrétaire-trésorier, le secrétaire-trésorier-désigné.

\section{Article VII: Le Bureau de direction}

7.1 Il y aura un Bureau de direction composé des membres suivants :

a) Le président, le président-désigné, le vice-président, le secrétaire-trésorier, le secrétaire-trésorier-désigné et le président-sortant;

b) les rédacteurs en chef de la Revue;

c) le président du comité du programme du congrès annuel;

d) douze autres membres, élus pour un mandat de deux ans, la moitié de ces membres étant élus à chaque assemblée annuelle de l'Association.

6.3 Sauf dans le cas du secrétaire-trésorier, la durée du mandat à chaque poste est d'une année, ou jusqu'à ce qu'un successeur soit choisi pourvu que le titulaire demeure admissible à réélection. La durée du mandat de secrétaire-trésorier est de trois ans, renouvelable pour un autre mandat ne dépassant pas trois ans. Si le titulaire ne se présente pas en réélection, le Bureau de direction demande au Comité des candidatures, au moins neuf mois avant le début de la dernière année du mandat du secrétaire-trésorier, de reçevoir les candidatures, au poste de secrétaire-trésorier-désigné, ce dernier occupant ce poste durant la dernière année du mandat du secrétaire-trésorier. 